\title{
Study on the Influence of Distribution Generation on Over Current Relays in Distribution Networks
}

\author{
Ning Zhou ${ }^{1}$, Xiang Lei ${ }^{2}{ }^{\text {a }}$, Xiaorui Jing ${ }^{1}$, Xiang $\mathrm{He}^{1}$, Zaibin $\mathrm{Jiao}^{2}$ \\ 1. Henan Electric Power Company Electric Power Research Institute, Zhengzhou 450000, Henan \\ 2. School of Electrical Engineering, Xi'an Jiaotong University, Xi'an 710049, Shaanxi, China \\ ${ }^{a}$ leixiang@stu.xjtu.edu.cn
}

Keywords: distributed generation; over current protection; DG type

Abstract: The application of Distributed Generation (DG) reduces the consumption of traditional energy, but it also brings certain challenge to relay protection because of its own characteristics. This paper analyzes that the injection or branching current will cause incorrect operation of over current protection. In addition, the paper also studies the short current output ability of different DG types. Simulation results show that the DG based on the inverter provides less short current than the synchronous type because of its output limiting link control strategy. Results from both simulation and experiments show that the proposed above is rational.

\section{Introduction}

With the depletion of fossil fuel and the constantly increasing demand for global energy, renewable energy has been used extensively ${ }^{[1-3]}$. Distributed generation can improve the utilization efficiency of the clean energy and solve the problem of electricity supply in remote rural areas by the use of renewable energy, such as wind power, solar energy and so on. This method has been one of the important measures to promote energy conservation and emission reduction and response to climate change in the world. But the original single power supply and radioactive structure characteristics of the power network will be changed with high penetration DG rate to distribution network, as a result, the power flow is no longer flowing in a single direction. This situation will directly change the amplitude and direction of short current, which has severe impact on existing overcurrent protection. Simultaneously, the random feature of distributed generation output, such as wind power and photovoltaic, makes relay setting difficult and even unable to meet the requirements of selectivity and speed. Nowadays, coping strategies adopted is that once the distribution network has a failure, all the DGs are removed immediately to ensure the correct action of relay protection. According to actual experience, $80 \%$ of the faults in the distribution network are transient faults, removing DGs blindly will restrict DG's normal operation and weaken the reliability of the power supply. From this, it is very important to put an adaptive overcurrent protection for distribution network with DG high penetration rate.

Many researchers have carried on thorough research to relay protection of DG connecting to distribution network. Reference [4-6] presents a strategy, which minimize distributed generation impact on current protection by installing short current limiter. Reference [7] puts forward an online setting strategy to overcurrent protection scheme which takes into account the fault severity and background of DG. Considering that the random feature of DG output makes it difficult for setting of current protection, reference [8] puts forward a distribution network protection strategy which setting value varies with the level of power output and fault current. In reference [9], in order to remove the influence of DG on setting value of protection, DG is equivalent to an injected current source and then utilizes matrix to calculate short current distribution. However, overcurrent 
protection may lose coordination and lead to the occurrence of exceeding-to-trip or failure-to-trip with high penetration.

In this paper, effect of different types of DG on short current is also studied. Results show that with the same penetration rate, the inverter DG capacity of injection current is small, which is due to the output limiting control strategy. The effect of different DG penetration on the positive and negative sequence impedance is also studied. The results show that the negative sequence impedance changes greatly during the fault period in this paper.

\section{Analysis of high penetration DG on overcurrent protection in distribution network}

The connected DG capacity in distribution system divided by the load capacity is usually defined as penetration rate $\mathrm{p}$, and the short current provided by system divided by that provided by DG is usually defined as stiffness ratio when fault occur. Generally speaking, when the penetration rate is greater than $10 \%$ and the stiffness ratio is less than 20 , the influence from the DG to the distribution network should be considered.

Fig. 1 shows a typical distribution network. The system source $S_{1}$ is connected to bus $A$, which supplies power to the radiate distribution network, and the distributed source $S_{D G}$ is connected to bus $\mathrm{B}$. The reference capacity of system is $100 \mathrm{MVA}$, and the rated voltage is $10.5 \mathrm{kV}$, the system equivalent reactance $\mathrm{Xs}=0.3 \mathrm{pu}$. The $\mathrm{DG}$ is inverter type, its equivalent reactance $\mathrm{X}_{\mathrm{DG}}=0.6 \mathrm{pu}$. The line resistance $\mathrm{r} 1=0.138 / \mathrm{km}$, and the reactance $\mathrm{x} 1=0.369 / \mathrm{km}$. The full length of the line is $10 \mathrm{~km}$. The load connecting to bus D and B is 0.95 MVA respectively, and the bus E and C is 2 MVA respectively.

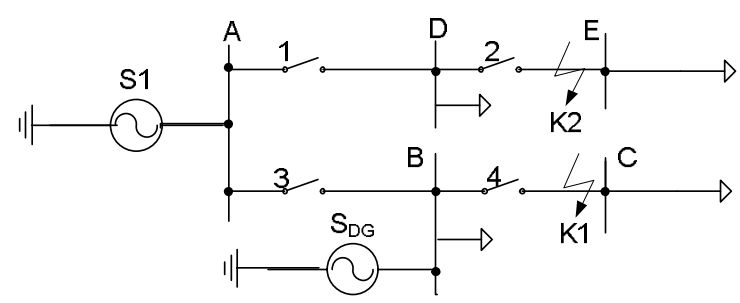

Fig.1 Typical distribution network structure

\section{1) The influence of DG on downstream line protection}

Fig. 1 shows that when a three phase fault occurs at K1, the system source $S_{1}$ and the distributed generation $S_{\mathrm{DG}}$ will both supply short current to fault point at the same time. The fault current detected by protection 4 will increase compared with the condition without $\mathrm{S}_{\mathrm{DG}}$. That is to say, the distributed generation provides injection current to protection 4.

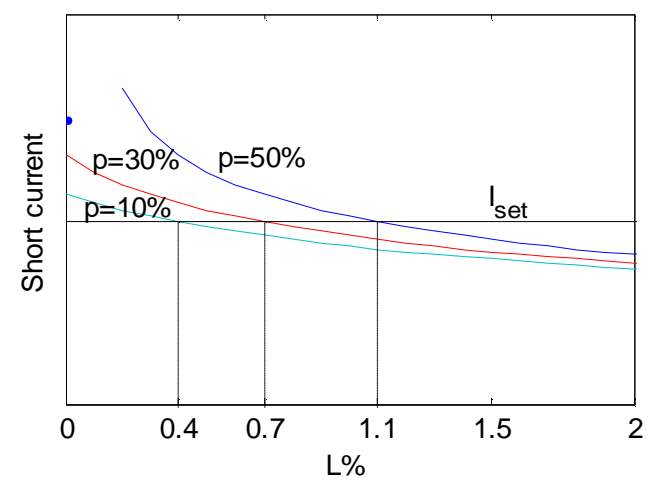

Fig.2 Effect of different penetration on protection 4

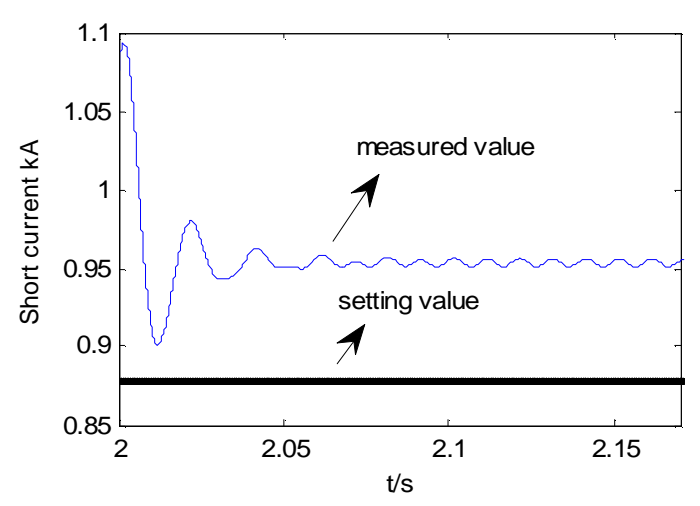

Fig.3 Effect of the injection current on protection 4 
At present, the penetration of DG is comparatively small in the distribution network. Meanwhile, DG connected to the network usually with electronic device, such as photovoltaic, which can limit the fault current. So the injection current brought by DG can enhance the sensitivity of protection 4, as shown in Tablel. But with high penetration rate of DG, such as the penetration rate $\mathrm{p}=50 \%$, the protection zone extends to the next line, as shown in Fig.2 (L\% means percentage of line length). The protection of the faulted line may operate incorrectly due to the injection current when a fault occurs in downstream line.

For the protection 4, when the fault occurred at $K_{1}$ which is at the end of line $B C$, fault current through protection 4 will increase as the injection current by DG. When the DG penetration is high, the measured current of protection 4 will be larger than its setting value, then it will mal-operate, as shown in Fig.3.

\section{2) The influence of DG on upstream line protection}

When a three phase fault occurs at K1 in Fig.1, the system source $S_{1}$ and distributed generation $\mathrm{S}_{\mathrm{DG}}$ will supply short current to the fault point. The line BC current and the voltage of bus B will increase, thus, the short current from the system source will decrease, as shown in Tablel. The sensitivity of protection 3 will be weakened and the protection even will operate incorrectly due to the branching current. Relay 3, as the backup protection, will refuse to act when malfunction of the main protection occurs.

TABLE I.

Simulation RESUlts WHEN FAULT OCCURS AT BUS $C$

\begin{tabular}{c|c|c}
\hline P/MW & Protection 4/kA & Protection3 $/ \boldsymbol{k A}$ \\
\hline 0 & 1.640 & 1.637 \\
\hline 0.5 & 1.631 & 1.655 \\
\hline 1 & 1.623 & 1.671 \\
\hline 1.5 & 1.619 & 1.680 \\
\hline 2 & 1.616 & 1.689 \\
\hline 5 & 1.582 & 1.754 \\
\hline
\end{tabular}

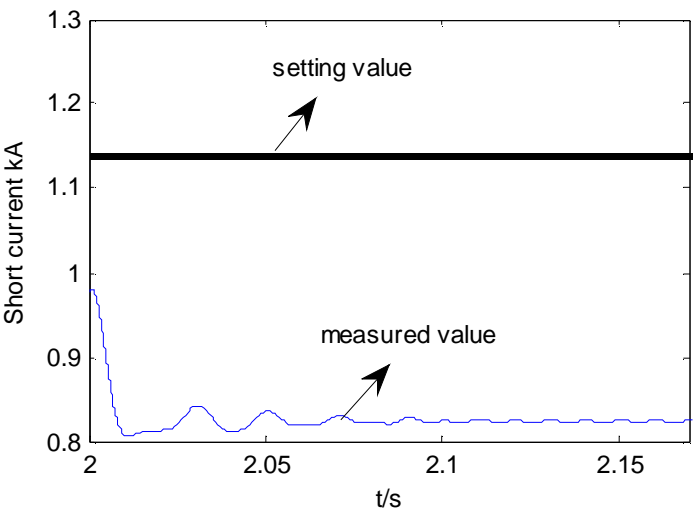

Fig.4 Effect of the branching current on protection 3

For the protection 3, when the fault occurred at beginning of line $B C$, fault current through protection 3 will decrease as the branching current by DG. When the DG penetration is high, the measured current of protection 4 will less than its setting value, then it will mal-operate, as shown in Fig.4.

\section{3) The influence of DG on current protection of adjacent feeder}

When three phase fault occurs at K2 in Fig.1, voltage drop caused by fault current mainly occurs on the line $\mathrm{AE}$ as the equivalent impedance of the system source is much less than the line impedance, then the voltage of bus $A$ is changed little. Meanwhile, the short current from $S_{\mathrm{DG}}$ is much smaller, so the protection 1 and 2 are not almost affected.

\section{4) Effect of different types of DG on short current}

According to the characteristics of DG connecting to distribution network, DG will be divided into conventional rotary type DG and inverter type DG, and different DG types make different fault transient performance. 
TABLE II.

FAULT CURRENT INJECTION ABILITY OF DiFFERENT DGS

\begin{tabular}{c|c}
\hline DG Type & Fault Current Injection Ability \\
\hline Converters & $100 \%-400 \%$ \\
\hline Synchronous Machines & $500 \%-1000 \%$ \\
\hline Induction Machines & $500 \%-1000 \%$ \\
\hline
\end{tabular}

The inverter type DG connects to distribution network by inverter, so it can not supply too much short circuit currents limited by DG inverter's output limiting link control strategy. Usually, short circuit currents supplied by inverter type DG will be 1.2 times than the normal rated current, as shown in Fig.5. On the contrary, the conventional rotary type DG can supply more current than inverter type DG. So research on different types DG connecting to distribution network has great significance. Tablellshows the fault current injection ability of different DGs.

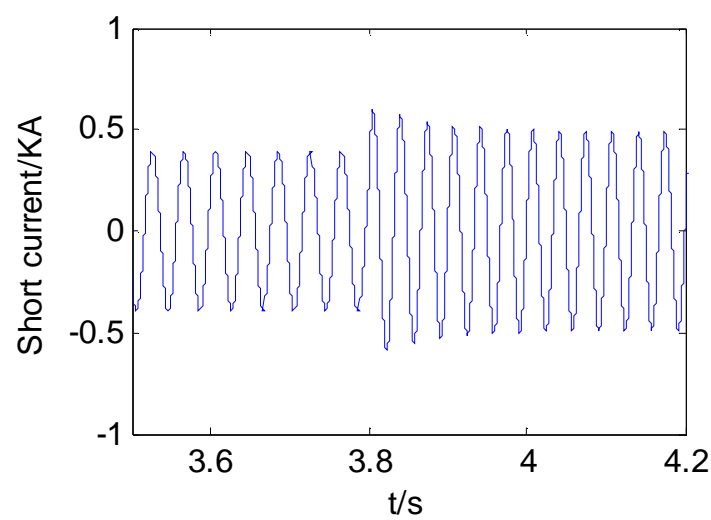

Fig. 5 Short current by converter DG

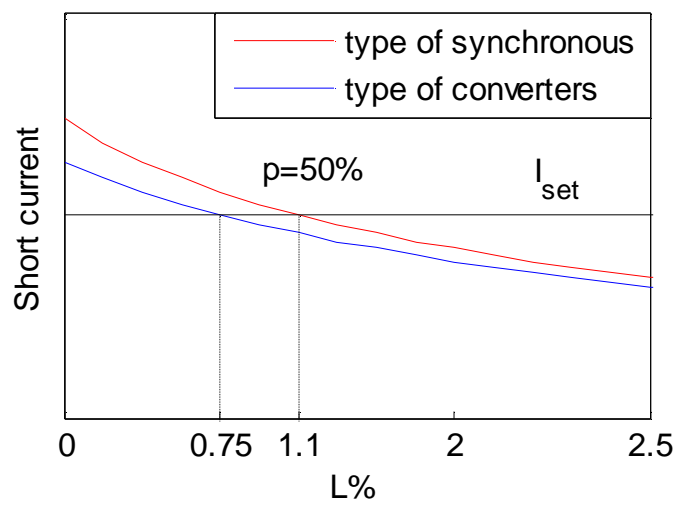

Fig. 6 Different types DGs fault current injection ability

Fig. 6 shows that the injection current ability between converter types DG and synchronous types DG when the penetration rate $\mathrm{p}=50 \%$. Result shows that with the same penetration rate, the inverter DG capacity of injection current is small, which is due to the limited control strategy. Therefore, in practice, the influence of inverter DG on the overcurrent protection can be less considered.

\section{Effect of high penetration DG on the positive and negative impedance}

This paper also studies the positive and negative sequence impedance change with DG penetration rate. When the DG penetration is $30 \%$ and $50 \%$ respectively, the positive and negative impedance are shown in Fig.7 and 8. 


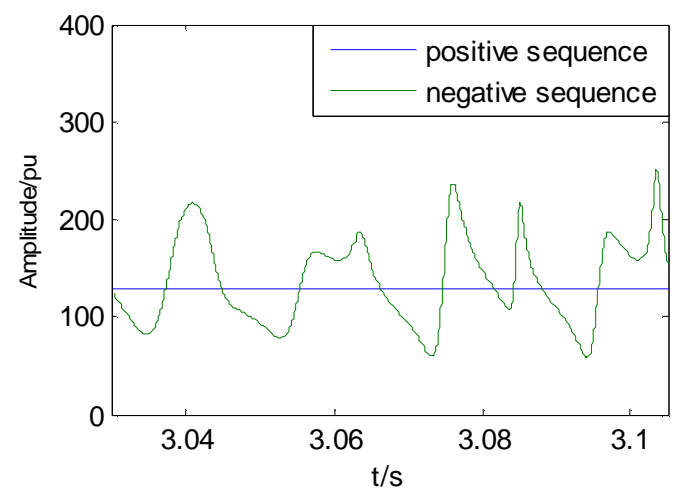

Fig.7 Impedance change with DG $30 \%$ penetration

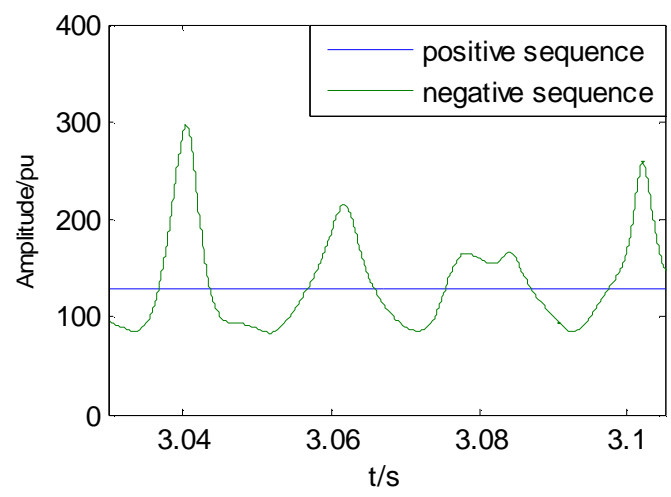

Fig.8 Impedance change with DG 50\% penetration

As shown in Fig.7 and Fig.8, when DG is connected to the distribution network with 50\% penetration rate, its positive impedance is steady basically during the fault, but the changes of negative impedance is relatively great. During the fault time, negative impedance will be greater as the penetration rate of DG increases, and then the setting calculation based on the negative sequence impedance would be influenced.

\section{Summary}

With increasing capacity of distributed power supply, the injection current and branching current will cause incorrect operation of over current protection, so the influence brought by distributed power should be considered in the actual relay setting. In addition, compared with synchronous type DG, the inverter types support limited short current, due to its output limiting link control strategy. But it is still necessary to study the new principle to adapt to high penetration DG in distribution network.

\section{References}

[1] Han Yi, Zhang Dongxia . Fault analysis of microgrid composed by inverter-based distributed generations $[\mathrm{J}]$. Power System Technology , 2011 , 35(10) : 68-73 .

[2] Fu Liwei, Wang Shouxiang, Zhang Yongwu . Optimal selection and configuration of multi-types of distributed generators in distribution network[J] . Power System Technology, $2012,36(1): 79-84$.

[3] Liang Caihao, Duan Xianzhong . Distributed generation and its impact on power system[J] . Automation of Electric Power Systems , 2001 , 25(12) : 53-56 .

[4] G. Tang and M. R. Iravani, "Application of a fault current limiter to minimize distributed generation impact on coordinated relay protection," presented at the Int. Conf. Power Syst. Transients, Montreal, QC,

[5] A. Agheli, H. A. Abyaneh, R. M. Chabanloo, and H. H. Dezaki, "Reducing the impact of DG in distribution networks protection using fault current limiters," in Proc.4th Int. Power Eng. 
Optimiz. Conf., 2010, pp.298-303.

[6] W. El-khattam and T. S. Sidhu, "Resolving the impact of distributed renewable generation on directional overcurrent relay coordination: A case study," IET Renew. Power Gen., vol. 3, pp. 415-425, 2009.

[7] N. Schaefer, T. Degner, A. Shustov, T. Keil, and J. Jaeger, "Adaptive protection system for distribution networks with distributed energy resources," presented at the 10th IET Int. Conf. Develop. Power Syst. Protect., Manchester, U.K., 2010.

[8] YU Qiong, YU Sheng, LI Xiaohui, et al. Adaptive protection solutions of distribution network with distributed power [J]. Power System Protection and Control, 2012, 40(5): 110-115.

[9] Ma Jing ,Wang Xi ,Mi Chao ,et al A new adaptive protection approach for distribution network containing distributed generation[J] . Power System Technology , 2011 , 35(10) : 204-209 . 